\title{
A temática do lazer em cursos de graduação da área da saúde
}

\author{
Marcos Filipe Guimarães Pinheiro ${ }^{1}$ \\ Christianne Luce Gomes ${ }^{2}$ \\ ${ }^{1}$ Centro Universitário Metodista Izabela Hendrix, Belo Horizonte, MG, Brasil \\ ${ }^{2}$ Departamento de Educação Física, Escola de Educação Física, da UFMG, Belo \\ Horizonte, MG, Brasil
}

\begin{abstract}
Resumo: Este artigo apresenta alguns resultados da pesquisa que teve como objetivo compreender de que maneira a temática do lazer é abordada no âmbito do ensino nos cursos de graduação em Educação Física, Fisioterapia e Terapia Ocupacional da Universidade Federal de Minas Gerais, Brasil. A metodologia foi baseada em pesquisa bibliográfica e documental, que envolveu análise dos projetos políticopedagógicos e programas de disciplinas. Foi possível constatar diferentes abordagens, visões e funções do lazer. Para a Educação Física o lazer é observado a partir de aspectos teórico-práticos, de atuação e formação profissional. Na Terapia Ocupacional destacam-se as possibilidades de inclusão/integração social, socialização, exercício de cidadania, desenvolvimento pessoal; possibilidades de experiências prazerosas, de brincadeiras, atividades lúdicas, utilizadas como meios e fins médicos/terapêuticos. Na fisioterapia, é possível perceber um viés voltado para a reabilitação onde o lazer, por meio do brincar, é tratado apenas como uma ferramenta utilizada em alguns momentos do tratamento fisioterápico.
\end{abstract}

Palavras-chave: Lazer. Saúde. Educação Física. Fisioterapia. Terapia Ocupacional.

\section{The theme of leisure in graduate health care}

\begin{abstract}
This article presents some results of research aimed at understanding how the theme of leisure is addressed in teaching in undergraduate courses in Physical Education, Physiotherapy and Occupational Therapy, Federal University of Minas Gerais, Brazil. The methodology was based on bibliographic and documentary research, which involved analysis of educational policy projects and programs of disciplines. It was possible to see different approaches, views and functions of leisure. Physical Education for leisure is observed from the theoretical and practical aspects of performance and training. In occupational therapy there are the possibilities of inclusion / social integration, socialization, citizenship, personal development opportunities for pleasant experiences, games, recreational activities, used as a media and medical / therapeutic. In physical therapy, it is possible to perceive a bias toward the rehabilitation where the fun through the play is treated as just one tool used in physical therapy a few moments.
\end{abstract}

Key-words: Leisure. Health. Physical Education. Physiotherapy. Occupational Therapy.

\section{Introdução}

Como mostram os estudos de Werneck (2000), Gomes e Melo (2003), gradativamente, cresce o número de áreas de conhecimento que se dedicam aos estudos sobre o lazer. De acordo com o site de busca textual do Diretório de Grupos de Pesquisa no Brasil, do Conselho Nacional de Desenvolvimento Científico e Tecnológico (CONSELHO NACIONAL..., 2009), a quantidade de grupos que estudam a temática do lazer vem crescendo. No censo realizado em 2000 havia 283 grupos que continham o lazer como palavra-chave da produção e/ou da linha de pesquisa. No último censo, feito em 2006, já existiam 957 grupos. Estes estão em áreas como Administração, Arquitetura e Urbanismo, Antropologia, Ciência da Informação, Economia, Educação, Educação Física, Fisioterapia e Terapia Ocupacional, Psicologia, Serviço Social,
Sociologia, Turismo, entre outras, abordando o tema sob diferentes aspectos (SOUZA, 2005). Algumas vezes, oportunizando brechas para discussões multi e interdisciplinares a respeito do lazer e suas relações dialéticas com as demais dimensões da vida humana como, por exemplo, o trabalho, a religião, a educação, a família, a política; bem como ao longo das diferentes fases da vida, como na infância, velhice, fase adulta, juventude. Aprofundando os conhecimentos a partir de temas como esses, os cursos na área da saúde, como a Educação Física, a Fisioterapia e a Terapia Ocupacional vem pesquisando e vivenciando o lazer na formação de seus(as) profissionais.

Nesse sentido, Marcellino (1996) aponta para uma especialização dos estudos do lazer, seguindo uma tendência observada também em 
outras esferas do conhecimento, quer em termos de faixa etária, quer por conteúdos de atividades. Hoje é possível encontrar inúmeros trabalhos que investigam o lazer na infância (CARVALHO et al., 2005; DEBORTOLI, 1999, 2004; PINTO, 2007), o lazer de idosos (PINHEIRO, 2007; PINHEIRO; GOMES, 2007), a formação profissional (ISAYAMA, 2003, 2005; WERNECK, 1998), ou que tenham como objeto de estudo as atividades físico-desportivas (CAVALCANTI, 1982; CARVALHO, 2001; ISAYAMA, 2007), artísticas (EAMPOS, 2007), turísticas (SEREJO, 2003), médicas-terapêuticas (PIGNOLATO FILHO; GOMES, 2001; XAVIER; FONSECA, 2007; BLASCOVI-ASSIS, 1997; LORENZINI, 1999; PINTO, 2009).

Todavia, o desenvolvimento dessa produção de conhecimento no âmbito do lazer, no país, é relativamente recente, e fomentado por diversos fatores. Entre eles, destaca-se a formação de grupos de estudos e pesquisa, a produção de livros e periódicos que disseminam e compartilham os trabalhos produzidos, os cursos de pós-graduação, tanto lato quanto stricto sensu, os cursos de formação profissional que buscam além de formar, qualificar os(as) profissionais que lidam com o lazer; os eventos acadêmicos científicos tendo a temática do lazer como eixo central, e também, a discussão e a elaboração de políticas públicas nos âmbitos municipais, estaduais e federais (GOMES; MELO, 2003), como citado anteriormente.

Tendo início na primeira metade do século $X X$, a produção teórica no campo do Lazer em nosso país precisa não apenas de ganhos quantitativos, mas principalmente de qualitativos. De acordo com Werneck (2000, p. 80), de uma maneira geral, "aqueles que se dedicam à pesquisa sobre objetos 'desvalorizados' em nosso meio - tais como o lazer - precisam atentar para os detalhes comprometedores do discurso em torno da 'seriedade' científica da área". Tomando como ponto de partida as produções realizadas na área da saúde, isso se agrava ainda mais, uma vez que, já legitimada, esta área do conhecimento, muitas vezes, (re)produz discursos de verdade que Ihe são próprios. Segundo Foucault (2006), tornar ciência é conferir efeitos de poder, atribuídos à ciência e àqueles que formulam um discurso científico.

Ao receber mais considerações a seu respeito e sendo cada vez mais incorporado a diversas instâncias e saberes, entre eles, o acadêmico, no chamado campo de estudos do lazer, temas como recreação, brincar, jogo ${ }^{1}$, lúdico ${ }^{2}$, entre outros, passam a ser amplamente estudados e pesquisados por diversas áreas do conhecimento, dentre elas a saúde. Entre tantos trabalhos produzidos por vários autores e autoras que se dedicaram a essas temáticas, podemos citar: Debortoli (1999, 2004, 2005), Gomes (2004, 2008), Marcellino (2003), Pinto (2007), Silva (2004) e Werneck (2003). O brincar pode ser visto como ferramenta ou como expressão (PEREIRA, 2005). Dessa maneira, brinca-se por brincar, brinca-se para aprender, brinca-se para sarar. Por tudo isso, no âmbito do lazer, as atividades físicas, o brincar, os jogos e as brincadeiras, seus usos e significados, passam a ser alvo de debate, intervenções e estudos acadêmicos.

No campo da saúde, muitos acadêmicos/as, docentes, pesquisadores/as e profissionais têm atuado com diversos aspectos do lazer, até mesmo, sem se darem conta disso. Por meio de jogos, brincadeiras, dentre outras atividades tidas como lúdicas, muitas intervenções são realizadas com pessoas de diferentes idades, com múltiplos fins. Portanto, torna-se importante entender os sentidos que o tema do lazer possui, e vem adquirindo, em cursos de formação na área da saúde para se pensar o processo de formação profissional, e também, a atuação profissional.

Para compreender alguns destes aspectos, foi realizada uma pesquisa de mestrado $^{3}$ que se debruçou sobre os seguintes questionamentos: De que maneira a temática do lazer integra os currículos dos cursos de graduação em Educação

\footnotetext{
1 Neste trabalho, os termos brincar e jogo são considerados segundo a perspectiva de Huizinga (1980). Segundo o autor, o jogo pode ser caracterizado como uma "atividade livre, conscientemente tomada como 'não-séria' e exterior à vida habitual, mas ao mesmo tempo capaz de absorver o jogador de maneira intensa e total. É uma atividade desligada de todo e qualquer interesse material, com a qual não se pode obter qualquer lucro, praticada dentro de limites espaciais e temporais próprios, segundo uma certa ordem e certas regras" (HUIZINGA, 1980, p. 16).

2 Concordo com Debortoli (1999), Gomes (2004) e Pereira (2005), para quem a ludicidade é uma forma de linguagem, ou seja, uma maneira do ser humano se expressar, referenciada no brincar, na brincadeira. De acordo com Pereira (2005), qualquer objeto pode se tornar um brinquedo. Não existe artefato lúdico, mas sim, a relação que o individuo estabelece com o objeto é que é lúdica.

${ }^{3}$ A pesquisa de mestrado mencionada tem como título Inserção da temática Lazer nos currículos dos cursos de graduação em Educação Física, Fisioterapia e Terapia Ocupacional da Universidade Federal de Minas Gerais (PINHEIRO, 2009) e foi defendida e aprovada pelo programa de pós-graduação stricto sensu em Lazer da UFMG. A pesquisa analisou as ações de pesquisa e de extensão realizadas pelos três cursos pesquisados. Entretanto, o presente artigo apresenta os resultados relacionados somente às atividades de ensino.
} 
Física, Fisioterapia e Terapia Ocupacional da Escola de Educação Física, Fisioterapia e Terapia Ocupacional (EEFFTO) da Universidade Federal de Minas Gerais (UFMG)? Quais conhecimentos sobre este tema integram as ações de ensino nesses cursos? Quais os sentidos são dados ao lazer neste contexto? Essas três áreas apresentam, através de seus currículos na EEFFTO, possibilidades de integração por meio da temática do lazer?

Este artigo objetiva, assim, compreender de que maneira a temática lazer é abordada no âmbito do ensino nos cursos de graduação em Educação Física, Fisioterapia e Terapia Ocupacional da EEFFTO/UFMG.

\section{Metodologia}

Esta investigação de natureza qualitativa combinou a pesquisa bibliográfica e a pesquisa documental. A primeira foi realizada principalmente por meio de livros, entretanto, também foram utilizados artigos de revistas e periódicos, coletâneas e anais de eventos, teses e dissertações, entre outros. Essas buscas foram efetuadas nos bancos de dissertações e teses do portal Capes $^{4}$ e da Universidade Estadual de Campinas (Unicamp) ${ }^{5}$ e na rede de bibliotecas da UFMG $^{6}$ a partir dos seguintes termos-chave: Lazer, Saúde, Educação Física, Fisioterapia, Terapia Ocupacional. A pesquisa documental foi realizada com base na análise dos projetos político-pedagógicos dos cursos e dos programas das disciplinas obtidos por meio de solicitações.

Aos Colegiados e/ou Departamentos (no caso da Educação Física) dos cursos foram solicitados os projetos Político Pedagógicos de cada curso e os programas de todas as disciplinas ofertadas nos anos de 2008 e 2009 nos três cursos analisados - Educação Física, Fisioterapia e Terapia Ocupacional.

Do colegiado do curso de Educação Física, foram encaminhados por e-mail os projetos Político Pedagógicos da Licenciatura e do Bacharelado (Graduação), estando este último, ainda em processo final de elaboração. Foram

\footnotetext{
${ }^{4}$ Disponível em:

$<$ http://servicos.capes.gov.br/capesdw/Teses.do >.

${ }^{5}$ Disponível em:

$<$ http://libdigi.unicamp.br/document/list.php?tid=7>.

6 O sistema de bibliotecas da UFMG pode ser acessado pelo link <http://webpergamum.adm-

serv.ufmg.br/pergamum/biblioteca/index.php.> Deste site é possível consultar grande parte do acervo de todas as bibliotecas da universidade.
}

enviados também 65 programas de disciplinas, sendo 42 pelo Departamento de Esportes e 23 pelo Departamento de Educação Física ${ }^{7}$.

O Colegiado do curso de Fisioterapia enviou, também por e-mail, seu ementário contendo 52 disciplinas, entre obrigatórias e optativas ofertadas por diversos outros colegiados $\mathrm{e}$ departamentos, e disponibilizou o seu Projeto Político Pedagógico para ser copiado por xerox.

O Colegiado de Terapia Ocupacional por sua vez, enviou 53 programas de disciplinas, mas informou, infelizmente, que não conseguiu localizar o seu Projeto Político Pedagógico. Entre todos os programas de disciplinas enviados, estavam disciplinas optativas e obrigatórias, oferecidas por diferentes departamentos de diversas unidades da UFMG. Todavia, na delimitação do objeto do estudo optou-se por analisar apenas os programas das disciplinas ofertadas pela EEFFTO, unidade acadêmica focalizada nesta pesquisa.

A partir daí foram analisados o título de cada disciplina, a ementa, os conteúdos programáticos, os objetivos e as referências, além de outras possíveis informações relevantes para efetuar o recorte e a análise dos documentos selecionados. Para isso, as buscas focalizaram termos como lazer, recreação, lúdico(a), brincadeira(s), brinquedo(s), jogo(s), dentre outros, mais detalhados a seguir. Após análises, e selecionadas aquelas disciplinas que tinham relação com o lazer, alguns daqueles tópicos, quando necessário, foram descritos para melhor elucidação do contexto onde estavam inseridos.

Por meio da análise dos Projetos Político Pedagógicos, tivemos acesso a elementos da história da criação e implementação dos cursos, às disciplinas com suas ementas, a avaliações anteriores dos cursos, aos objetivos dos cursos e perfil almejado dos egressos, entre outros. O Projeto Político Pedagógico do curso de Educação Física estava bem fundamentado e desenvolvido. No caso da Fisioterapia, foi apresentado um documento sucinto, composto basicamente pela grade curricular e programas

\footnotetext{
7 O curso de graduação em Educação Física da UFMG, na EEFFTO, é constituído por dois departamentos: o Departamento de Esportes (DESP) e o Departamento de Educação Física (DEF). Embora muitas das disciplinas ligadas ao ensino da Educação Física sejam de responsabilidade do DEF e muitas disciplinas relacionadas ao ensino e treinamento de modalidades esportivas sejam desenvolvidas pelo DESP, trata-se de uma divisão meramente administrativa no contexto desta unidade acadêmica da UFMG.
} 
das disciplinas. No caso da Terapia Ocupacional, lamentavelmente o Projeto Político-Pedagógico do curso não foi localizado pela secretaria, de modo que a análise ficou restrita aos programas de disciplinas.

A fim de melhor compreender a inserção da temática nos currículos desses três cursos, todos os documentos colhidos foram discutidos $e$ analisados à luz das teorias e dos conceitos apresentados durante a pesquisa bibliográfica, por meio da construção iterativa de uma explicação. Esta estratégia faz parte do modelo de análises qualitativas de conteúdo propostas por Laville e Dionne (1999). De acordo com estes autores, a análise qualitativa de conteúdo permite que $o(a)$ pesquisador(a) se prenda

às nuanças de sentido que existem entre essas unidades, aos elos lógicos entre essas unidades [...] visto que a significação de um conteúdo reside largamente na especificidade de cada um de seus elementos e na relação entre eles, especificidade que escapa amiúde ao domínio do mensurável (LAVILLE; DIONNE, 1999, p. 227).

Como mostra Foucault (2006), uma das formas de o poder se estabelecer e funcionar é através da produção, acumulação, circulação e funcionamento do discurso que o produz e que 0 reproduz. E já se sabe, o currículo constrói identidades e subjetividades. A partir da abordagem e do ensino de uma determinada temática, seja a educação física, o lazer, ou qualquer outra, um conteúdo biomédico, bem como pela exclusão desses saberes, espera-se (re)formar determinado indivíduo. Em currículos, sobretudo de formação profissional, é possível moldar interesses, perspectivas e atitudes. "Junto com os conteúdos das disciplinas escolares, se adquirem na escola percepções, disposições e valores que orientam os comportamentos e estruturam as personalidades" (PARAísO; SANTOS, 1996, p. 35).

Com base em tais constructos metodológicos foram realizadas as análises documentais, interpretações e considerações apresentadas a seguir.

\section{Resultados e Discussão}

O quadro abaixo lista, em ordem alfabética, todas as disciplinas cujos programas explicitam algum(s) dos termos buscados e que, por este motivo, foram selecionadas, totalizando 37 disciplinas com temáticas relacionadas ao lazer, ministradas nos currículos dos três cursos estudados.
Da graduação em Educação Física, considerando ambos os departamentos Educação Física e Esportes foram enviados 65 programas de disciplinas e analisadas 21. Foi possível identificar um trato teórico-prático dado ao lazer, tendo em vista seus aspectos conceituais, históricos, políticos e metodológicos, bem como as atividades práticas, as vivências e experiências de lazer. Podem-se perceber também maneiras diferentes e, algumas vezes, dicotômicas de se abordar o lazer. Mesmo que o termo jogo surja em algumas disciplinas, elas geralmente estavam relacionadas e voltadas para o ensino de modalidades esportivas e para os processos de treinamento dessas modalidades, em seus aspectos técnicos, táticos e psicológicos. O jogo, na maioria das vezes é utilizado como sinônimo de esporte, ou das atividades de ensino e prática de determinada modalidade esportiva. Isso pode ser evidenciado, por exemplo, nestas citações de ementas de alguns programas de disciplinas: "Comportamento básico da defesa e ataque no jogo com marcação individual" (Ensino de Basquetebol); "História; técnicas; fundamentos do jogo; processos de aprendizagem" (Ensino do Voleibol) e "História; Processos de ensinoaprendizado-treinamento da área formal e não formal do Esporte Handebol" (Ensino de Handebol).

Debortoli (2004) esclarece que toda brincadeira consiste num jogo, no sentido de construção e instauração de certas regras e de uma dinâmica coletiva de significação. Todavia, nem todo jogo é uma brincadeira. "Nem todo jogo se expressa como possibilidade de reconstrução e ressignificação da realidade" (p. 20).

Já os termos lúdico, brincadeira, ou brincar, são utilizados, aparentemente, como elemento motivacional, prazeroso e minimizador do caráter maçante de exercícios repetitivos para a aprendizagem e treinamento. Dois exemplos disso são: uma referência da disciplina Ensino de Handebol (MELHEM, A. Brincando e aprendendo Handebol. 2. ed. Rio de Janeiro: Sprint, 2004.) e um tópico dos conteúdos da disciplina Ginástica: "Brincadeiras lúdicas de aquecimento". De acordo com Debortoli (2004), as brincadeiras pedagógicas são aquelas que se esforçam para dar um tom mais agradável àquilo que se quer ensinar. Tal discurso carrega consigo o paradoxo de que o que se tem para fazer, para se conhecer e aprender é tão monótono que é preciso outra roupagem para se tornar mais agradável. Assim, 
percebe-se que o tema lazer possui pontos de intercessão com outras temáticas, como já dito, o lúdico, o brincar, entre outras.

As atividades físicas de uma maneira geral, incluindo os mais diferentes esportes, integram, por sua vez, os chamados conteúdos físico- esportivos do lazer. Nesse sentido, Isayama (2007) afirma que tais atividades constituem uma das possibilidades de práticas culturais mais difundidas em nosso meio na atualidade. Seja praticando as atividades, seja consumindo, assistindo, como público espectador.

Quadro 1. Disciplinas selecionadas e departamento/curso responsável

\begin{tabular}{|c|c|c|}
\hline DISCIPLINA & RESPONSABILIDADE & TERMO ENCONTRADO \\
\hline Antropologia e Educação Física & Departamento de Esportes & Lúdico \\
\hline Atividade e desenvolvimento humano I & Departamento de Terapia Ocupacional & $\begin{array}{l}\text { Recreação; brincar; brinquedos; } \\
\text { jogos }\end{array}$ \\
\hline Atividade e desenvolvimento humano II & Departamento de Terapia Ocupacional & $\begin{array}{l}\text { Atividades lúdicas; jogos; } \\
\text { brincadeiras }\end{array}$ \\
\hline Cinesioterapia - Terapia Ocupacional & Departamento de Terapia Ocupacional & Lazer; brincando \\
\hline Educação Física A & Departamento de Fisioterapia & Lazer; recreação \\
\hline Educação Física e Lazer & Departamento de Educação Física & Lazer \\
\hline Educação Física, Lazer e Juventude & Departamento de Educação Física & Lazer \\
\hline Ensino de Basquetebol & Departamento de Esportes & Jogo \\
\hline Ensino de danças contemporâneas & Departamento de Educação Física & Lazer \\
\hline Ensino de Handebol & Departamento de Esportes & Jogo; brincando \\
\hline Ensino de jogos, brinquedos e brincadeiras & Departamento de Educação Física & Brincadeiras; brinquedos; jogos \\
\hline Ensino do Voleibol & Departamento de Esportes & Jogo \\
\hline Fisioterapia aplicada à Pediatria II & Departamento de Fisioterapia & Brincar; brincadeiras \\
\hline $\begin{array}{l}\text { Formação e atuação profissional na } \\
\text { Educação Física }\end{array}$ & Departamento de Educação Física & Lazer \\
\hline Formação e atuação profissional no lazer & Departamento de Educação Física & Lazer \\
\hline Fundamentos de Terapia Ocupacional & Departamento de Terapia Ocupacional & Lazer \\
\hline Futebol e Cultura & Departamento de Educação Física & Lazer \\
\hline Ginástica & Departamento de Esportes & Brincadeiras lúdicas \\
\hline História da Educação Física & Departamento de Educação Física & Lazer \\
\hline Introdução à Recreação e estudos do Lazer & Departamento de Educação Física & Lazer; recreação \\
\hline Metodologia do Ensino da Educação Física & Departamento de Esportes & Atividades físicas e recreativas \\
\hline Movimento e desenvolvimento humano I & Departamento de Fisioterapia & Lazer \\
\hline Movimento e desenvolvimento humano II & Departamento de Fisioterapia & Lazer; brinquedo; brincadeiras \\
\hline Psicologia do Esporte & Departamento de Esportes & Esporte recreativo \\
\hline $\begin{array}{c}\text { Questão afetiva e social da Educação } \\
\text { Física }\end{array}$ & Departamento de Educação Física & Brincar \\
\hline Recursos Terapêuticos I & Departamento de Terapia Ocupacional & Atividades lúdicas; brinquedos \\
\hline Recursos Terapêuticos II & Departamento de Terapia Ocupacional & Lazer; jogos \\
\hline Sociologia do Esporte & Departamento de Esportes & Tempo Livre (Lazer) \\
\hline Teoria da Atividade Física Adaptada & Departamento de Esportes & Lazer; recreacional; recreation \\
\hline Teoria de Jogos & Departamento de Terapia Ocupacional & Lazer; lúdico; recreação; brincar \\
\hline Teoria e prática dos esportes I & Departamento de Esportes & Jogo \\
\hline Teoria e prática dos esportes II & Departamento de Esportes & Jogo \\
\hline $\begin{array}{l}\text { Terapia Ocupacional aplicada à saúde } \\
\text { mental e à psiquiatria }\end{array}$ & Departamento de Terapia Ocupacional & Brinquedo; jogo \\
\hline $\begin{array}{c}\text { Terapia Ocupacional aplicada ao } \\
\text { desenvolvimento A }\end{array}$ & Departamento de Terapia Ocupacional & Lazer \\
\hline $\begin{array}{c}\text { Terapia Ocupacional aplicada ao } \\
\text { desenvolvimento B }\end{array}$ & Departamento de Terapia Ocupacional & Lazer \\
\hline $\begin{array}{c}\text { Terapia Ocupacional aplicada às disfunções } \\
\text { neurológicas }\end{array}$ & Departamento de Terapia Ocupacional & Lazer \\
\hline $\begin{array}{l}\text { Terapia Ocupacional aplicada às disfunções } \\
\text { orgânicas gerais }\end{array}$ & Departamento de Terapia Ocupacional & Lazer \\
\hline
\end{tabular}


O colegiado do curso de graduação em Fisioterapia da UFMG enviou o ementário, contendo o programa completo de 52 disciplinas, obrigatórias e optativas, mas só quatro tinham algum tipo de relação com o lazer. Além da escassez de referências específicas sobre lazer nos programas consultados, analisando os objetivos de uma disciplina (Fisioterapia aplicada à pediatria Il) que trata do brincar e da brincadeira, é possível perceber alguns aspectos importantes:

Capacitar o estudante a reconhecer e avaliar disfunções de estruturas e funções do corpo e de atividades típicas da criança, decorrentes de condições que afetam os sistemas neurológico e musculoesquelético, propor intervenções para minimizar ou corrigir tais disfunções; ou ainda propor intervenções preventivas; analisar os resultados da intervenção fisioterapêutica e documentar a evolução do quadro clínico (PROJETO PEDAGÓGICO ..., [2003, p.106).

Estes dados evidenciam que o brincar e a brincadeira são utilizados, na disciplina, como recursos terapêuticos à pediatria, essa especialidade médica. A ideia central é perceber as disfunções que devem ser tratadas a partir de tais atividades, consideradas "típicas das crianças".

Sobre este aspecto, é relevante destacar que a prática terapêutica na área da saúde precisa ser repensada constantemente no sentido de humanizá-la, como apontam Blascovi-Assis, Peixoto e Reis (2001). Entretanto, uma das barreiras enfrentadas é a supervalorização dos conteúdos, numa concepção limitada de saúde, tidos como terapêuticos nos cursos de graduação da área da saúde em geral. A necessidade de manutenção da saúde e bem-estar da população, onde a saúde torna-se objetivo geral e dever de cada individuo, trouxe uma súbita importância para a medicina (FOUCAULT, 2006), e, posteriormente, para áreas que nasceram sob a influência médica.

De acordo com Baudrillard (1995), a prática medical não tem perdido sua superioridade. "Apesar de 'democraticamente consumida', a medicina nada perdeu do seu sagrado e da sua funcionalidade mágica" (BAUDRILLARD, 1995, p. 148). Isto pode ser constatado desde os períodos iniciais do surgimento das três áreas abordadas neste estudo, porém, talvez seja mais evidenciado, atualmente, no contexto da Fisioterapia, como pode ser percebido na ênfase privilegiada dos conteúdos biomédicos de seu currículo formal.

Tomando como base as ementas das disciplinas que constam no Projeto Pedagógico da Fisioterapia nota-se, de uma forma geral, que o currículo deste curso direciona-se para o estudo de patologias, doenças infecciosas, doenças degenerativas, deformidades, deficiências, incapacidades, síndromes, disfunções, amputações, distúrbios e transtornos. A partir desses problemas, são abordadas medidas profiláticas e a aplicação de exames, avaliações, diagnósticos, métodos, técnicas e recursos para tratamento e prevenção (PROJETO PEDAGÓGICO ..., [2003]).

Dessa maneira, pode-se observar o caráter curativo e reabilitador que permeia a formação do(a) fisioterapeuta na instituição estudada. $O$ que vai ao encontro da legislação vigente que regula a área, tanto no âmbito da formação, como, e principalmente, da sua atuação. No Decreto-Lei 938 , art. $3^{\circ}$, encontra-se que "é atividade privativa do fisioterapeuta executar métodos e técnicas fisioterápicos com a finalidade de restaurar, desenvolver e conservar a capacidade física do ciente". Diferentemente do/a terapeuta ocupacional que pode ter possibilidades mais amplas, pois, de acordo com o mesmo decreto no art. $4^{\circ}$, deve "executar métodos e técnicas terapêuticas e recreacional com a finalidade de restaurar, desenvolver e conservar a capacidade mental do paciente" (BRASIL, 1969). Além disso, - Parecer n ${ }^{\circ} 388 / 63$ destaca a participação dos, até então, denominados Técnicos em Fisioterapia e Terapia Ocupacional, exclusivamente na aplicação de técnicas e exercícios recomendados pelos médicos, que busquem a cura e/ou a recuperação dos parcialmente inválidos para a vida social (REBELATTO; BOTOMÉ, 1999).

Conforme apontam Rebelatto e Botomé (1999, p.63), os documentos oficiais relativos ao profissional de Fisioterapia, com exceção, talvez, do seu Código de Ética Profissional, parecem ter sidos elaborados sob a ótica da concepção saúde-doença. Tais documentos, em nenhum momento, citam ou deixam transparecer "os diversos níveis, tipos ou âmbitos de atuação que esse profissional poderia ou deveria exercer ao atuar na 'assistência' as condições de saúde de um individuo ou de uma comunidade". Portanto, os autores afirmam que o ensino superior não pode ser apenas um espaço para o ensino de 
técnicas e capacidades para o auxílio a outros(as) profissionais.

Numa concepção ampliada da relação saúdedoença estão envolvidos, de forma complexa, diversos aspectos psicológicos, físicos, sociais e ambientais da condição humana e de atribuições de significado. Saúde e doença são fenômenos clínicos e sociológicos, pois são vividos culturalmente, experimentados e ressignificados pela sociedade. Assim, saúde e doença, "importam tanto pelos seus efeitos no corpo como pelas suas repercussões sobre o imaginário: ambos são reais em suas conseqüências" (MINAYO, 2004, p. 16).

Portanto, não é possível, como destaca esta autora, dissociar-se de qualquer forma de tratamento, de qualquer procedimento terapêutico, os aspectos subjetivos das pessoas, seus valores e suas crenças. Negligenciando, silenciando temas sócio-culturais, como o lazer, no currículo, a Fisioterapia pode correr o risco de formar profissionais cada vez mais sob uma perspectiva médica tradicional. Há, portanto, para o currículo da graduação em Fisioterapia, perspectivas reais de uma maior humanização, e o lazer pode ser um dos caminhos possíveis.

Neste sentido, são pertinentes as considerações de Deslandes (2004) sobre humanização. De acordo com a autora, a humanização constitui um novo campo de possibilidades, tanto para o aumento da qualidade da assistência quanto para uma nova perspectiva relacional, pautada no reconhecimento da alteridade e no diálogo. Tal concepção de humanização corrobora com 0 entendimento demarcado na Política Nacional de Humanização $(\mathrm{PNH})$, que requer a valorização dos diferentes sujeitos implicados no processo de "produção" de saúde, usuários/as, trabalhadores/as e gestores/as; fomento da autonomia e do protagonismo desses sujeitos; aumento do grau de co-responsabilidade na produção de saúde e de sujeitos; estabelecimento de vínculos solidários e de participação coletiva no processo de gestão; identificação das necessidades de saúde; mudança nos modelos de atenção e gestão dos processos de trabalho tendo como foco as necessidades das pessoas e a produção de saúde; compromisso com a ambiência, melhoria das condições de trabalho e de atendimento (DESLANDES, 2005).
Em um conto de Walter Benjamin é possível visualizar a importância da humanização nas práticas de saúde a partir de outras possibilidades que vão além das técnicas curativas tradicionais do saber médico, um aspecto que necessita, cada vez mais, ser problematizado na formação dos profissionais da área da saúde.

A criança está doente. A mãe a leva pra cama e
se senta ao lado. E então começa a lhe contar
histórias. Como se deve entender isso? [...]
Também já se sabe como o relato que o
paciente faz ao médico no início do tratamento
pode se tornar o começo de um processo
curativo. Daí vem a pergunta se a narração não
formaria o clima propício e condição mais
favorável de muitas curas, e mesmo se não
seriam todas as doenças curáveis se apenas
deixassem flutuar para longe - até a foz - na
correnteza da narração. Se imaginarmos que a
dor é uma barragem onde se opõe à correnteza
da narrativa, então vemos claramente que é
rompida onde sua inclinação se torna
acentuada o bastante para largar tudo o que
encontra em seu caminho ao mar ditoso do
esquecimento. É o carinho que delineia um leito
para essa corrente. (BENJAMIN, 1994, p. 269)

Abordando o tema do lazer em um ambiente hospitalar, Pinto (2009) destaca os diversos papéis que as atividades lúdicas podem adquirir num contexto de sofrimento. Dentre as várias possibilidades apontadas pela autora, ela percebeu, no caso específico do hospital, a ocupação do tempo, a liberação da dor, o relaxamento, a fuga do tédio, entre outras. Questões que, apesar de legítimas, considerando este contexto, podem ser ampliadas. Assim, todos esses aspectos podem ser complementares à ideia de ressignificação do lazer, de desenvolvimento pessoal e social.

$\mathrm{Na}$ Terapia Ocupacional, das 53 disciplinas acessadas analisou-se 12. Dessas disciplinas, muitas trazem a possibilidade de um estudo mais consistente sobre o lazer no currículo, como observado, também, no currículo da Educação Física, uma vez que o tema é abordado de uma forma direta. Uma ênfase considerável é dada, quando se aborda o tema do lazer, ao aspecto da "integração social" de indivíduos com algum tipo de deficiência, a saber: problemas cardíacos, amputados, com algum tipo de má formação, deficientes mentais, visuais e auditivos. Entre as atividades terapêuticas propostas para $o(a)$ terapeuta ocupacional, estão: tecelagem, tricô, crochê, costura, bordado, macramê, cestaria, marcenaria, pirografia, jardinagem, horticultura, culinária, jogos de salão e ao ar livre, jogos de 
mesa, jogos corporais, jogos pedagógicos, dança, música, teatro, modelagem, desenho e pintura.

O mesmo decreto citado anteriormente (Decreto-Lei 938), porém no artigo 4ํㅡㄹ afirma que "é atividade privativa do terapeuta ocupacional executar métodos e técnicas terapêuticas e recreacional com a finalidade de restaurar, desenvolver e conservar a capacidade mental do paciente" (Ênfase acrescentada). Nota-se que a legislação no caso da Terapia Ocupacional já orienta seus/as profissionais a atuarem recreativamente.

Os trabalhos, atividades e estudos desenvolvidos com pessoas com algum tipo de deficiência se apresentam como uma possibilidade de projetos e ações interdisciplinares entre os cursos analisados. Vários estudos vêm demonstrando, por exemplo, a importância dessas atividades para as pessoas com algum tipo de deficiência mental. Tanto no campo do Lazer, como nos campos da Terapia Ocupacional, da Educação Física e da Fisioterapia (PIGNOLATO FILHO; GOMES, 2001; XAVIER, FONSECA, 2007; BLASCOVI-ASSIS, 1997; LORENZINI, 1999).

Não há problemas, obviamente, em se trabalhar o processo saúde-doença nas disciplinas e currículos dos cursos de Fisioterapia e Terapia Ocupacional. O desafio é tratar deste processo de forma ampliada, por exemplo, reconhecendo o lazer como um dos determinantes da saúde. Essa compreensão é apontada por alguns documentos públicos, entre eles o artigo 3o da Lei no. 8.080 (BRASIL, 1990), e a recente Política Nacional de Promoção da Saúde (BRASIL, 2006). Tais documentos afirmam o lazer como um dos fatores determinantes e condicionantes da saúde. Embora haja referências legais para a promoção do lazer no âmbito da saúde, Pinto (2009, p. 168) chama a atenção para o fato de que "a formação profissional em saúde pouco esclarece sobre a importância do lazer e sobre as suas contribuições para a vida das pessoas".

Acredita-se que as práticas de saúde nos três cursos analisados poderiam ser (re)pensadas, procurando contemplar com mais profundidade a questão da humanização. No caso específico da Fisioterapia, as ações de ensino poderiam se aproximar mais dos princípios norteadores e dos objetivos apresentados no Projeto Pedagógico do curso $^{8}$, que são interessantes, mas que nem sempre condizem com os programas das disciplinas ofertadas e que integram o currículo deste curso.

Nesse sentido, Blascovi-Assis, Peixoto e Reis (2001) apresentam um projeto de humanização no campo da Fisioterapia. As autoras mostram serem necessários novos perfis na formação universitária. A terapia deve ser um lugar agradável e não de desprazer. Um paciente motivado, além de não abandonar o tratamento, se envolve nele e recupera-se mais rapidamente. Segundo as autoras, "algumas disciplinas relacionadas à formação educacional deste profissional", na graduação, "acabam sendo pouco valorizadas pelos próprios docentes, ficando a grande ênfase naquelas que proporcionam um enfoque essencialmente médico" (BLASCOVI-ASSIS; PEIXOTO; REIS, 2001, p. 128).

Estas autoras apontam o(a) fisioterapeuta como um(a) educador(a). Educa-se, "os hábitos posturais, as rotinas de estimulação ao desenvolvimento, a disposição de mobiliários em indústrias ou em residências, o tipo de brinquedo, roupa ou acessório que facilita a independência no dia a dia." Mas, nos currículos deste curso, "por estar caracteristicamente vinculado à saúde, pouca ênfase tem sido dada à sua formação enquanto educador" (BLASCOVI-ASSIS; PEIXOTO; REIS, 2001, p. 128). Olhando além de técnicas, tem-se um papel formador de pessoas mais capacitadas para tratar dignamente seus pacientes, atuando na comunidade como agentes educadores, quer voltados para a promoção, quer para a prevenção em diferentes níveis ${ }^{9}$.

\footnotetext{
8 De acordo com o Projeto Pedagógico do Curso de Fisioterapia ([2003], p.12), o objetivo do curso é "formar profissionais da saúde dentro dos princípios da integralidade na atenção e no cuidado à saúde e da prática baseada em evidências, favorecendo a articulação dos conhecimentos e o trabalho em equipe multiprofissional, além de promover atividades práticas ao longo de todo o curso e em todos os tipos de unidades de saúde".

9 É importante ressaltar que prevenção e promoção de saúde não são sinônimos. As estratégias de prevenção da saúde relacionam-se mais às doenças e profilaxias, ocorrendo nos níveis primário, secundário e terciário. A promoção da saúde é mais ampla e visa o desenvolvimento de pessoas, melhor entendimento e cuidados com a saúde e bem-estar, valoriza a sociabilização e a relação com ambiente envolvendo não apenas o indivíduo, mas também, sua família e outros grupos. Além disso, a promoção da saúde é multidimensional e intersetorial, contemplando assim, educação, trabalho, lazer, saneamento, habitação, alimentação, meio ambiente e renda, entre vários outros aspectos. Baseada nas políticas de saúde do Brasil, Pinto (2009) esclarece que promover saúde significa ampliar 0 entendimento do processo
} 
Segundo Carvalho (2005), vivenciar a dimensão lúdica da vida, estimular a capacidade criativa e inventiva das pessoas e dos grupos por meio das atividades esportivas, do teatro, das atividades artísticas e dos jogos - é investir na qualidade de vida e nas condições de saúde. Assim, seja na busca pelo brincar, pelo simples fato de brincar, pelas brincadeiras com um fim em $\mathrm{si}$, pelas atividades com objetivos de desenvolver atividades críticas e/ou criativas; ou então, por intermédio dessas atividades, com o escopo de apenas minimizar uma dor ou uma deficiência qualquer, de contribuir para uma "aceitação" de determinada situação ou de um tratamento, o lazer se mostra possível.

\section{Conclusão}

Os documentos analisados permitiram concluir que ocorrem diferentes abordagens teóricopráticas de alguns aspectos do lazer nos currículos dos três cursos pesquisados. No caso da Educação Física esta abordagem ocorre tendo em vista trabalhar, com os/as discentes, aspectos conceituais, históricos, políticos e metodológicos, bem como atividades práticas e experiências de lazer. Foi possível constar também a coexistência de maneiras diferentes e, algumas vezes, divergentes de se abordar o lazer.

Mesmo que o termo jogo seja enfatizado em algumas disciplinas, elas geralmente estavam vinculadas ao ensino de esportes e a processos de treinamento esportivo. Neste sentido, o jogo é freqüentemente tratado como sinônimo de esporte, ou das atividades de ensino e prática de determinada modalidade esportiva. Já os termos lúdico, brincadeira, ou brincar, são utilizados, aparentemente, como elemento motivacional, prazeroso e minimizador do caráter maçante de exercícios repetitivos para a aprendizagem e treinamento físico-esportivo, procurando conferir um tom mais agradável àquilo que se quer ensinar.

As práticas terapêuticas no âmbito do ensino no curso de Fisioterapia estudado poderiam ser repensadas constantemente, no sentido de serem cada vez mais comprometidas com a humanização e com uma concepção ampliada de saúde. Entretanto, uma das barreiras enfrentadas é a supervalorização, numa concepção limitada de saúde, dos conteúdos tidos como terapêuticos

saúde/adoecimento, conjugando clínica e política, atenção e gestão.

Motriz, Rio Claro, v.17, n.4, p.579-590, out./dez. 2011 em alguns cursos de graduação da área da saúde, como destacado no decorrer deste artigo.

Em geral, os programas das disciplinas observadas apresentam espaços, mesmo que reduzidos, para discussões acerca das subjetividades e particularidades dos seres humanos em busca de melhores condições de saúde, dos significados dos tratamentos e da relação saúde-doença para diferentes sujeitos.

Os termos pesquisados e explicitados nos programas do curso de fisioterapia estudado tais como lazer, recreação, brinquedo e brincadeira - parecem ser utilizados como ferramentas auxiliares dos/as profissionais nos tratamentos e procedimentos clínicos com pacientes infantis. Dessa maneira, pode-se observar um caráter curativo e reabilitador na formação do(a) fisioterapeuta no curso investigado.

No que se refere ao curso de Terapia Ocupacional investigado, muitas das disciplinas que foram analisadas evidenciaram, em seus programas, a possibilidade de um estudo mais consistente sobre o lazer no currículo. Quando o tema do lazer era abordado nesses programas, destaca-se sua relação com 0 aspecto da "integração social" de indivíduos com algum tipo de deficiência.

Entre as atividades terapêuticas propostas para o(a) terapeuta ocupacional, são apresentadas várias possibilidades, dentre as quais a tecelagem, o tricô, a costura, a marcenaria, a jardinagem, a culinária, jogos de salão e ao ar livre, dança, música, teatro, modelagem, desenho e pintura, entre várias outras. Ressaltam-se também as lacunas existentes nas disciplinas que se propõem a estudar temas como o lazer, o brincar, o brinquedo e o jogo, pois, a partir das análises efetuadas nos programas, especialmente na bibliografia que fundamenta cada disciplina, foi possível constatar que estas temáticas nem sempre são aprofundadas.

Os currículos dos três cursos de graduação analisados abordam o assunto da intervenção com pessoas com deficiência, tanto física quanto mental. Seja no âmbito do ensino, da pesquisa e da extensão, com centros e/ou grupos de estudos e pesquisas e com laboratórios, a EEFFTO apresenta possibilidades de intervenções e ações, estudos e pesquisas, tanto multi, como 
interdisciplinares. Foi constatado o desafio de trabalhar o processo saúde-doença nas disciplinas e nos currículos dos investigados de forma ampliada. Por exemplo, reconhecendo o lazer como um dos fatores determinantes e condicionantes da saúde (BRASIL, 1990).

A partir de um esforço para se abrir a novos conceitos, novas ideias e perspectivas, são possíveis importantes avanços para 0 crescimento e desenvolvimento do lazer enquanto campo de estudos. Uma formação qualificada, a partir de uma perspectiva mais crítica e mais inclusiva, preocupada, também, com aspectos humanizadores, portanto, históricos, culturais, sociais e políticos, facilitaria uma maior compreensão acerca do lazer, possibilitando outras abordagens curriculares para este tema no âmbito da saúde, indo além de uma perspectiva meramente utilitarista.

\section{Referências}

\section{BAUDRILLARD, Jean. A sociedade de consumo. Lisboa: Edições 70, 1995.}

BENJAMIN, Walter. Rua de mão única. 4. ed. São Paulo: Brasiliense, 1994.

\section{BLASCOVI-ASSIS, Silvana Maria. Deficiência mental e lazer. Campinas: Papirus, 1997.}

BLASCOVI-ASSIS, Silvana Maria; PEIXOTO, Beatriz de Oliveira; REIS, Conceição Aparecida S. O grupo fisioalegreterapia e a preocupação com a motivação nos atendimentos terapêuticos. Licere, Belo Horizonte, v. 4, n. 1, p. 127-134, 2001.

BRASIL. Decreto no 938 de 13 de outubro de 1969. Provê sobre as profissões de fisioterapeuta e terapeuta ocupacional, e dá outras providências. Previdência da República: Casa Civil. Brasília, 13 de outubro de 1969. Disponível em: $<$ https://www.planalto.gov.br/ccivil_03/decretolei/1965-1988/Del0938.htm>. Acesso em: 26 out. 2009.

BRASIL. Lei n 8080 de 19 de setembro de 1990 . Dispõe sobre as condições para a promoção, proteção e recuperação da saúde, a organização e o funcionamento dos serviços correspondentes e dá outras providências. Previdência da República: Casa Civil. Brasília, 19 de setembro de 1990. Disponível em: <

https://www.planalto.gov.br/ccivil_03/leis//8080.ht m>. Acesso em: 26 out. 2009.

BRASIL. Ministério da Saúde. Secretaria de Vigilância em Saúde. Política nacional de promoção da saúde. Brasília: Ministério da Saúde, 2006.
CAMPOS, Marcos Antônio A. Histórias

entrelaçadas: presença da dança na escola de educação física da UFMG (1952-1977). 2007.

Dissertação (Mestrado em Educação) Universidade Federal de Minas Gerais, Minas Gerais, 2007.

CARVALHO, Alysson Massote et al.

Brincar(es). Belo Horizonte: UFMG, 2005.

CARVALHO, Yara Maria. Atividade física e saúde: onde está e quem é o "sujeito" da relação?

Revista Brasileira de Ciências do Esporte,

Porto Alegre, v. 22, n. 2, p. 9-21, jan. 2001.

CARVALHO, Yara Maria. Lazer e saúde. Brasília: SESI, 2005.

CAVALCANTI, Kátia Brandão. Esporte para todos: um discurso ideológico. 1982. Dissertação (Mestrado em Educação Física) - Universidade Federal do Rio de Janeiro, Rio de Janeiro, 1982.

CONSELHO Nacional de Desenvolvimento Científico e Tecnológico (CNPq). Busca textual: diretório de grupos de pesquisa no Brasil. Disponível em: <http://dgp.cnpq.br/buscagrupo/>. Acesso em: 17 fev. 2009.

DEBORTOLI, José Alfredo. Brincadeira. In: GOMES, Christianne L. (Org). Dicionário crítico do lazer. Belo Horizonte: Autêntica, 2004, p. 1924.

DEBORTOLI, José Alfredo. Com olhos de crianças: a ludicidade como dimensão fundamental da construção da linguagem e da formação humana. Licere, Belo Horizonte, v. 2, n. 1, p. 105-117, 1999.

DEBORTOLI, José Alfredo. Educação infantil e conhecimento escolar: reflexões sobre a presença do brincar na educação de crianças pequenas. In: CARVALHO, Alysson Massote et al.

Brincar(es). Belo Horizonte: Editora UFMG, 2005, p. $65-80$.

DESLANDES, Suely Ferreira. Análise do discurso oficial sobre a humanização da assistência hospitalar. Ciência Saúde Coletiva, Rio de Janeiro, v. 9, n. 1, 2004 . Disponível em: $<$ http://www.scielosp.org/scielo.php?script=sci artt ext\&pid $=\$ 1413$ -

$81232004000100002 \& \operatorname{lng}=$ en\&nrm=iso $>$. Acesso em: 30 jan. 2011.

DESLANDES, Suely Ferreira. O projeto éticopolítico da humanização: conceitos, métodos e identidade. Interface (Botucatu), Botucatu, v. 9, n. 17, ago. 2005. Disponível em: $<$ http://www.scielo.br/scielo.php?script=sci arttext \&pid=S1414- 
32832005000200017\&lng=en\&nrm=iso >. Acesso em: 30 jan. 2011.

FOUCAULT, Michel. Microfísica do poder. 22. ed. Rio de Janeiro: Graal, 2006.

GOMES, Christianne Luce. Lazer: concepções. In: GOMES, Christianne Luce (Org). Dicionário crítico do lazer. Belo Horizonte: Autêntica, 2004, p. 119-126.

GOMES, Christianne Luce. Lazer, trabalho e educação: relações históricas, questões contemporâneas. 2. ed., rev. amp. Belo Horizonte: Editora UFMG, 2008.

GOMES, Christianne Luce; MELO, Victor Andrade de. Lazer no Brasil: trajetória de estudos, possibilidades de pesquisa. Revista Movimento. Porto Alegre, v. 9, n. 1, p. 23-44, 2003.

HUIZINGA, Johan. Homo ludens. 2. ed. São Paulo: Perspectiva, 1980.

ISAYAMA, Hélder Ferreira. Recreação e lazer na formação profissional em Educação Física: reflexões sobre o currículo. In: GOMES, Christianne L.; ISAYAMA, Hélder F. Lazer, recreação e educação física. Belo Horizonte: Autêntica, 2003, p. 173-214.

ISAYAMA, Hélder Ferreira. Reflexões sobre os conteúdos físico-esportivos e as vivências de lazer. In: MARCELLINO, Nelson Carvalho. Lazer e cultura. Campinas: Alínea, 2007, p. 31-46.

ISAYAMA, Hélder Ferreira. Um olhar sobre a formação profissional no lazer. Licere, Belo Horizonte, v. 8, n. 1, p. 11-19, 2005.

LAVILLE, Christian; DIONNE, Jean. A construção do saber: manual de metodologia da pesquisa em ciências humanas. Porto Alegre: Artmed, 1999.

LORENZINI, Marlene Valdicea. Brincando no ambiente natural: uma contribuição para o desenvolvimento sensório-motor da criança portadora de Paralisia Cerebral. 1999. Tese (Doutorado em Educação Física) - Faculdade de Educação Física, Universidade Estadual de Campinas, Campinas, 1999.

MARCELLINO, Nelson Carvalho. (Org.). Repertório de atividades de recreação e lazer: para hotéis, acampamentos, clubes, prefeituras e outros. 3 ed. Campinas: Papirus, 2003.

MARCELLINO, Nelson Carvalho. Estudos do lazer: uma introdução. Campinas: Autores Associados, 1996.
MINAYO, Maria Cecília de Souza. O desafio do conhecimento: pesquisa qualitativa em saúde. 8. ed. São Paulo: Hucitec, 2004.

PARAÍSO, Marlucy Alves; SANTOS, Lucíola Licínio de C. Dicionário crítico da educação: currículo. Presença Pedagógica, Belo Horizonte, v. 2, n. 7, jan./fev., 1996.

PEREIRA, Eugenio Tadeu. Brincar e criança. In: CARVALHO, Alysson Massote et al.

Brincar(es). Belo Horizonte: Editora UFMG, 2005, p. 17-27.

PIGNOLATO FILHO, Otávio Oswaldo; GOMES, Christianne Luce. Atividades físicas desportivas de lazer e o portador de deficiência mental. 2001. Monografia (Especialização em Lazer) - Universidade Federal de Minas Gerais, Belo Horizonte, 2001.

PINHEIRO, Marcos Filipe Guimarães. Inserção da temática Lazer nos currículos dos cursos de graduação em Educação Física, Fisioterapia e Terapia Ocupacional da Universidade Federal de Minas Gerais. 2009. 130f. Dissertação (Mestrado) - Escola de Educação Física, Fisioterapia e Terapia Ocupacional, Universidade Federal de Minas Gerais, Belo Horizonte, 2009.

PINHEIRO, Marcos Filipe Guimarães. Lazer e instituições asilares: reflexões baseadas na análise dos periódicos $A$ terceira idade e Revista Brasileira de Ciências do Esporte (2001-2005). 2007. Monografia (Graduação em Educação Física) - Escola de Educação Física, Fisioterapia e Terapia Ocupacional, Universidade Federal de Minas Gerais, Belo Horizonte, 2007.

PINHEIRO, Marcos Filipe Guimarães; GOMES, Christianne Luce. Lazer, velhice e instituição asilar: reflexões baseadas na revisão de literatura e nos trabalhos apresentados no Encontro Nacional de Recreação e Lazer (2001-2005). A Terceira Idade, São Paulo, v. 18, n. 40, p. 27-38, out. 2007.

PINTO, Gabriela Baranowski. O lazer em hospitais: realidades e desafios. 2009. Dissertação (Mestrado em Lazer) - Escola de Educação Física, Fisioterapia e Terapia Ocupacional, Universidade Federal de Minas Gerais, Belo Horizonte, 2009.

PINTO, Leila Mirtes Santos de M. Vivência lúdica no lazer: humanização pelos jogos, brinquedos e brincadeiras. In: MARCELLINO, Nelson Carvalho. Lazer e cultura. Campinas: Alínea, 2007, p. 171194.

PROJETO PEDAGÓGICO do curso de

Fisioterapia: Escola de Educação Física, 
Fisioterapia e Terapia Ocupacional. Universidade Federal de Minas Gerais. Belo Horizonte: Departamento de Fisioterapia, UFMG, [2003].

REBELATTO, José Rubens; BOTOMÉ, Sílvio Paulo. Fisioterapia no Brasil: fundamentos para uma ação preventiva e perspectivas profissionais. 2. ed. São Paulo: Manole, 1999.

SEREJO, Hilton Fabiano Boaventura. A gênese dos estudos do lazer num curso superior de turismo em Minas Gerais: um estudo na instituição pioneira : (1974-1985). 2003. 209f. Dissertação (Mestrado) - Pontifícia Universidade Católica de Minas Gerais, Belo Horizonte, 2003.

SILVA, Rogério Correia. Brinquedo. In: GOMES, Christianne L. (Org). Dicionário crítico do lazer. Belo Horizonte: Autêntica, 2004, p. 25-29.

SOUZA, Alexandre P. T. de. Lazer e educação física: analisando os grupos que adotam abordagem direta de pesquisa cadastrados na plataforma lattes do CNPq. 2005. Monografia (Graduação em Educação Física) - Escola de Educação Física, Fisioterapia e Terapia Ocupacional, Universidade Federal de Minas Gerais, Belo Horizonte, 2005.

XAVIER, Cecília Melo Neves; FONSECA, Marcos Aurélio. $O$ valor do lúdico para os adultos nas instituições psiquiátricas, considerações acerca da prática de terapia ocupacional. 2007. Monografia (Especialização) - Universidade Federal de Minas Gerais, Belo Horizonte, 2007.

WERNECK, Christianne Luce G. A constituição do lazer como um campo de estudos científicos no Brasil: implicações do discurso sobre a cientificidade e autonomia deste campo. In: ENCONTRO NACIONAL DE RECREAÇÃO E LAZER, 12., 2000, Balneário Camboriú.

Coletânea... Balneário Camboriú: Roca: Universidade do Vale do Itajaí, 2000. p. 77-88.

WERNECK, Christianne Luce G. A formação profissional no lazer em nossa moderna sociedade: Repensando os limites, os horizontes e os desafios para a área. Licere, Belo Horizonte, v. 1, n. 1, p. 47-65, 1998.

WERNECK, Christianne Luce G. Recreação e lazer: apontamentos históricos no contexto da Educação Física. In: GOMES, Christianne L.; ISAYAMA, Hélder F. Lazer, recreação e educação física. Belo Horizonte: Autêntica, 2003, p. $15-56$.
Endereço:

Marcos Filipe Guimarães Pinheiro

Centro Universitário Metodista Izabela Hendrix.

Rua Expedicionários, 600, Santa Amélia

Horizonte MG Brasil

31555-200

e-mail: marcosfgpinheiro@gmail.com

Recebido em: 3 de agosto de 2010.

Aceito em: 11 de março de 2011.

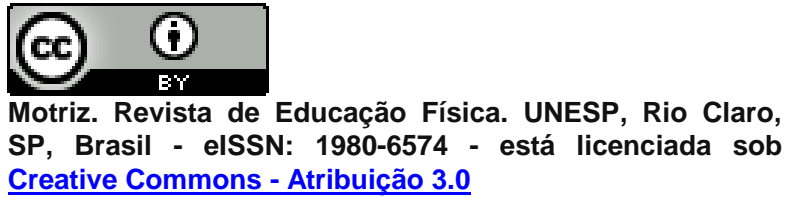

